demonstrated a most simple outpatient technique of excising the sinus and cleaning out any tracts under local anaesthesia. Over the last six years I have used this method for almost a hundred patients and the rate of recurrence has been negligible. The procedure takes less than 10 minutes, only a dry dressing is required, and many patients return to work the following day. Most patients can then attend to their own dressings, and one or two follow-up visits to the clinic are all that is required before discharge. Instead of six inpatient days with the foam elastomer sponge those treated by the "Lord" technique spend more like six minutes in the hospital. Victoria Hospital,
Blackpool

K M Dickinson

\section{Early thymectomy for myasthenia gravis}

SIR,-I have long accepted the value of early thymectomy in myasthenia gravis ${ }^{1}$ and I therefore read with interest Mr A E Kark's (6 September, p 593) and Mr C Grimshaw's (4 October, p 40) comments.

No one would deny that a less mutilating surgical procedure must benefit the patient (and also the surgeon), but what worries me is the likelihood that anything less than a full exposure of the anterior mediastinum may result in a procedure which is less than a total thymectomy. The following case illustrates this.

A woman aged 41 underwent trans-sternal thymectomy for generalised myasthenia A typical fleshy thymus gland weighing $10 \mathrm{~g}$ was removed. It must be stressed that the gland was clearly delineated and easily dissected in its entirety, and one would have been justified in assuming that the whole thymus had been removed. However, a final look round before closure revealed fatty masses on either side and extending into the lung hila. These were then dissected and also examined histologically. Section of the thymus revealed thymic tissue with areas of adipose tissue between lymphoid aggregates, germinal centers being very prominent. Section of both lateral fatty masses revealed adipose tissue with fragments of thymic tissue similar to the histological features noted in the main thymus gland.

While it is known that ectopic thymic tissue is not uncommon, the above findings have been noted and proved histologically on numerous occasions, and this is the main reason for my continuing to use the transsternal approach.

Royal Free Hospital,

M J LANGE

Lange, M M, British fournal of Surgery, 1960,
48, 285.

\section{Diagnosis of gastric cancer}

SIR,-The article by Dr A W Segal and others (21 June, p 669) emphasises the poor diagnostic yield of direct vision gastric biopsy in relation to gastric carcinoma. Their result of only $70 \%$ biopsy confirmation of carcinoma is by no means in keeping with experience in other centres. Kasugai reports a $92.8 \%$ positive biopsy correlation in 751 proved gastric carcinomas. ${ }^{1}$

In all but four of 130 gastric carcinomas examined by endoscopy at this hospital in just over four years the diagnosis was confirmed by biopsy evidence. Two of the patients with the false-negative biopsy results were recognised by the endoscopist to have advanced carcinoma. There were no falsepositive biopsies. We take 8-12 bites routinely of all doubtful or suspicious ulcers, using the Olympus GFB or JFB instruments. Our current policy is that surgery for cancer is not performed unless a positive biopsy report is obtained. However, if a lesion is suspected of being malignant endoscopy and biopsy are repeated until $x$-ray, endoscopy, and biopsy findings correlate.

Dr Segal and his colleagues do not refer to the problem of the diagnosis of early gastric cancer, which is so well recognised by Japanese workers. ${ }^{2}$

Despite the falling standardised mortality rate in Australia for gastric cancer ${ }^{3}$ the recognition of these early lesions does much to increase survival figures. In our experience with early gastric cancer ${ }^{4}$ the reliance on biopsy and its interpretation is paramount and the overall value of direct-vision gastric biopsy cannot be over-emphasised.

G S NAGY

P H R GREEN D I FEVRE

Gastroenterology Unit,

Royal North Shore Hospital,

Sydney, New South Wales

Kasugai, T, and Kobayashi, S, American fournal of Gastroenterology, 1974, 66, 199. Murakami, T, Pathomorphological Diagnosis, Gann Monograph II, p 53. Tokyo, University of Tokyo Press, 1974

Scott, G, Cancer Forum No 5, Australian Cancer

Council, August 1975, p 250.
Barrett, P J, et al, Gut. In press.

\section{Paradoxical effect of pindolol}

SIR,-Drs Hendrika J Waal-Manning and F O Simpson (19 July, p 155) report on nine cases among 260 hypertensive patients whose blood pressure (BP) fell when the dose of pindolol was reduced. From our experience with pindolol in hypertension the incidence of this so-called "paradoxical" effect may be more general than is suggested.

We have recently carried out a controlled study, ${ }^{1}$ in which a reduction of the pindolol dosage from about $30 \mathrm{mg}$ daily to about $20 \mathrm{mg}$ daily consistently gave a further reduction in blood pressure.

Of 38 patients with essential hypertension (WHO grade 1) with a diastolic BP of 100-129 $\mathrm{mg} \mathrm{Hg}, 20$ were treated with pindolol and 18 with propranolol for 14 weeks after an initial placebo period of four weeks. The patients were examined six times -initially, after the placebo period (visit 2), after a pretreatment period, after four weeks' treatment with the full dosage of pindolol (29 mg daily) or propranolol ( $232 \mathrm{mg}$ daily), after four weeks' further treatment with an individually adjusted dose of pindolol (average $29 \mathrm{mg}$ daily) or propranolol (average $241 \mathrm{mg}$ daily) (visit 5), and finally after a further four weeks' treatment during which the individual doses were reduced by onethird by the elimination of the midday dose so that patients received medication in the morning and evening only (visit 6).

The table shows how the BP changed between visits. At visit 5 the $\mathrm{BP}$ reductions on pindolol and propranolol were similar; further reductions followed on pindolol treatment when the dose was lowered and given only twice daily during the last four-week period. The results with propranolol were somewhat different: the systolic, diastolic, and mean pressure decreased up to visit 5 but increased again after dosage reduction and the change to twice-daily administration.

Per Bjerle K-A JACOBSSON G AGERT

Department of Clinical Physiology,

University of Ume

1 Bjerle, P, et al, Current Therapeutic Research. In press.

Serum cholesterol and enzyme-inducing agents

SIR,-We read with interest the report by Dr Risto Pelkonen and others (11 October, p 85) of increased serum cholesterol levels in patients receiving phenytoin. We have recently completed an investigation of the effects of phenobarbitone on serum lipids in healthy young volunteers (the results of which have been submitted for publication elsewhere). We similarly found a significant increase in the level of total serum cholesterol occurring within three weeks, which was entirely accounted for by a rise in low density lipoprotein cholesterol. Total serum triglycerides and very low density lipoprotein triglycerides were not altered, although a significant rise in low density lipoprotein triglycerides did occur. Evidence that drug-metabolising enzymes were induced was provided by a considerable increase in antipyrine clearance.

Microsomal enzyme induction, an effect of both phenobarbitone and phenytoin, would be a possible mechanism for the rise of serum cholesterol, since the rate-limiting enzyme for cholesterol biosynthesis, $\beta$-hydroxy- $\beta$-methylglutaryl-CoA reductase, is microsomally located. ${ }^{1}$ Increased hepatic and intestinal cholesterol synthesis has been produced experimentally in phenobarbitonetreated animals. ${ }^{2-4}$

Raised levels of serum cholesterol have previously been shown in persons receiving phenobarbitone, ${ }^{5}$ in children on anticonvulsant therapy, ${ }^{6}$ and in a patient undergoing medical treatment with phenobarbitone for gallstones. ${ }^{7}$ Therefore we would agree that a rise in serum cholesterol is a

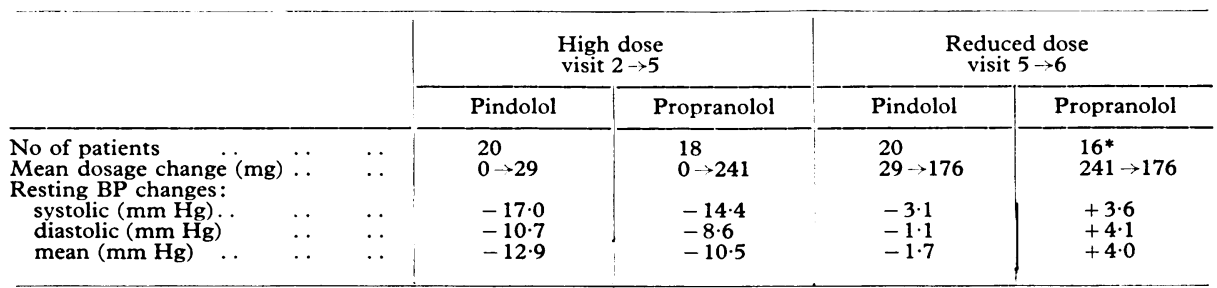

*Two patients were excluded since they did not follow the dosage instructions. 